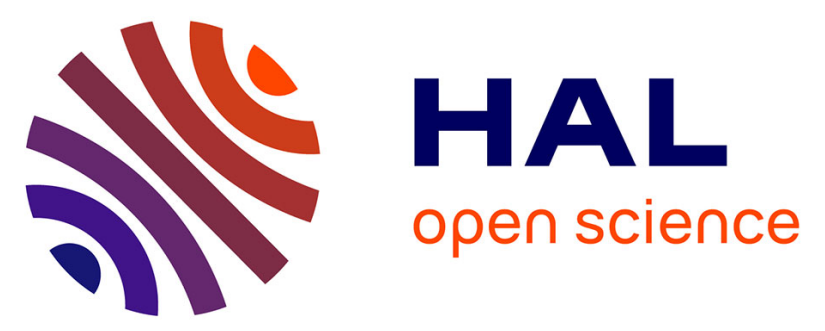

\title{
Synthesis and Computational Study of a Pyridylcarbene Fe(II) Complex: Unexpected Effects of fac / mer Isomerism in Metal-to-Ligand Triplet Potential Energy Surfaces
}

\author{
Antonio Francés-Monerris, Kevin Magra, Mohamed Darari, Cristina Cebrian, \\ Marc Beley, Edoardo Domenichini, Stefan Haacke, Mariachiara Pastore, \\ Xavier Assfeld, Philippe Gros, et al.
}

\section{- To cite this version:}

Antonio Francés-Monerris, Kevin Magra, Mohamed Darari, Cristina Cebrian, Marc Beley, et al.. Synthesis and Computational Study of a Pyridylcarbene Fe(II) Complex: Unexpected Effects of fac / mer Isomerism in Metal-to-Ligand Triplet Potential Energy Surfaces. Inorganic Chemistry, 2018, 57 (16), pp.10431 - 10441. 10.1021/acs.inorgchem.8b01695 . hal-01858716

\author{
HAL Id: hal-01858716 \\ https://hal.science/hal-01858716
}

Submitted on 30 Jan 2021

HAL is a multi-disciplinary open access archive for the deposit and dissemination of scientific research documents, whether they are published or not. The documents may come from teaching and research institutions in France or abroad, or from public or private research centers.
L'archive ouverte pluridisciplinaire HAL, est destinée au dépôt et à la diffusion de documents scientifiques de niveau recherche, publiés ou non, émanant des établissements d'enseignement et de recherche français ou étrangers, des laboratoires publics ou privés. 


\section{Synthesis and Computational Study of a Pyridylcarbene Fe(II) Complex: Unexpected Effects of fac/mer Isomerism in Metal-to- Ligand Triplet Potential Energy Surfaces}

Antonio Francés-Monerris, ${ }^{*}+\odot$ Kevin Magra, ${ }^{\ddagger}$ Mohamed Darari, ${ }^{\S}$ Cristina Cebrián ${ }^{\ddagger}$ Marc Beley, Edoardo Domenichini, ${ }^{\|}$Stefan Haacke, ${ }^{\|}$Mariachiara Pastore, ${ }^{\dagger}$ Xavier Assfeld, ${ }^{\dagger}$ Philippe C. Gros, ${ }^{\S}$ and Antonio Monari* ${ }^{*}+\circ$

${ }^{\dagger}$ Université de Lorraine, CNRS, LPCT, F54000 Nancy, France
${ }^{\ddagger}$ Université de Lorraine, CNRS, L2CM, F57000 Metz, France
${ }^{\S}$ Université de Lorraine, CNRS, L2CM, F54000 Nancy, France
${ }^{\|}$Université de Strasbourg-CNRS, UMR 7504 IPCMS, 67034 Strasbourg, France

Supporting Information

ABSTRACT: The synthesis and the steady-state absorption spectrum of a new pyridineimidazolylidene $\mathrm{Fe}$ (II) complex (Fe-NHC) are presented. A detailed mechanism of the triplet metal-to-ligand charge-transfer states decay is provided on the basis of minimum energy path (MEP) calculations used to connect the lowest-lying singlet, triplet, and quintet state minima. The competition between the different decay pathways involved in the photoresponse is assessed by analyzing the shapes of the obtained potential energy surfaces. A qualitative difference between facial $(f a c)$ and meridional ( $m e r)$ isomers' potential energy surface (PES) topologies is evidenced for the first time in iron-based complexes. Indeed, the mer complex shows a steeper triplet path toward the corresponding ${ }^{3} \mathrm{MC}$ minimum, which lies at a lower energy as compared to the fac isomer, thus pointing to a faster triplet decay of
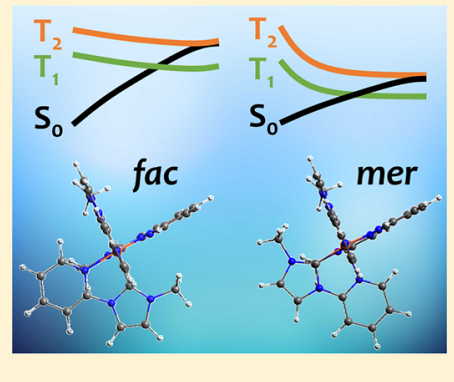
the former. Furthermore, while a major role of the metal-centered quintet state population from the triplet ${ }^{3} \mathrm{MC}$ region is excluded, we identify the enlargement of iron-nitrogen bonds as the main normal modes driving the excited-state decay.

\section{INTRODUCTION}

The development of photoactive molecular materials represents a key scientific task, with applications spanning many different domains, including solar energy conversion, ${ }^{1}$ molecular machines and switches, ${ }^{2,3}$ and luminescent devices. ${ }^{4}$ In the past few years, the progress made in all the previous domains has clearly allowed unprecedented scientific and technological breakthroughs and give rise to an impressive control and tuning of the different underlying complex photochemical and photophysical processes. However, development of highly efficient inorganic-based materials often necessitates the use of heavy and rare metals, such as ruthenium or platinum. This may strongly limit the accessibility of the so-obtained devices, while sensibly increasing their production costs and environmental impact. For such reasons, the possibility of using less toxic and abundant metals such as iron as the key constituents of optically active and luminescent devices represents an ideal target. Nevertheless, the photophysics of the first-row transition metal complexes can be significantly more challenging than that of the heavier elements. As an example, ruthenium(II) polypyridyl complexes are characterized by impressively long-lived metal-to-ligand (MLCT) triplet states, ${ }^{5}$ representing one of the most efficient classes of nonperovskite solar cells. ${ }^{1,6,7}$ On the contrary, the corresponding iron(II) counterparts experience a sub-picosecond relaxation to metal centered $(\mathrm{MC})$ states that ultimately lead to an ultrafast ground-state recovery. ${ }^{8}$ As a consequence, the photophysics of iron(II) compounds is almost nonexploitable. In a first approximation, this contrasting behavior can be ascribed to the different energy separation of the metal $d$ orbitals (ligandfield splitting) upon ligand coordination. In the case of secondrow ruthenium, its higher ligand-field splitting results in more destabilized MC states, that will be less prone to deactivate the luminescent low-lying MLCT states. ${ }^{9,10}$ This concept has recently been exploited by different groups to increase the excited state lifetime of iron complexes. ${ }^{1-22}$ In particular, the substitution of typical pyridine ligands with strong electrondonating carbenes has allowed considerable breakthroughs. Indeed, tridentate pyridine/carbene iron(II) complexes have been synthesized leading to MLCT lifetimes of tens of picoseconds, ${ }^{11,12,15-17}$ and only very recently has a record of 528 ps lifetime been reported by Wärnmark and Sundström's group. ${ }^{18}$ On the other hand, the introduction of grafting moieties on these complexes and the subsequent functionalization of $\mathrm{TiO}_{2}$ surfaces has also allowed the production of solar cells, whose capacity to convert solar light into electricity,

Received: June 20, 2018

Published: July 31, 2018 
although weak, has been clearly demonstrated. ${ }^{12,15}$ From a more fundamental point of view, the general photophysics of octahedral iron complexes has been experimentally characterized for instance by Damrauer's group, ${ }^{23}$ who exploited the quintet state of highly strained polypyridine complexes to increase the excited states lifetime.

Even if partially successful, the simple interpretation based on the ligand-field splitting is way too oversimplified to allow a full understanding of the iron(II) complexes photophysics. Hence, it fails to guide a fully rational molecular designing process. In particular, the PESs of the different MC and MLCT states along the pathways leading to relaxation should be carefully explored, and the different electronic and structural factors modifying its topology should be taken into account. It is worth noting that the photophysics of iron complexes has been studied both experimentally and computationally, in the latter case via the characterization of the excited-state potential energy surfaces (PESs) including also the location of minimum energy crossing points in the framework of photoinduced spin crossover and, more generally, iron photophysical deactivation. ${ }^{19,24-27}$ A recent review by Ashley and Jakubikova details the computational efforts performed by various research groups to understand iron complexes photophysics. ${ }^{28}$

In this contribution we consider a novel $N$-heterocyclic carbene complex (Fe-NHC, see Figure 1). The PESs of all the

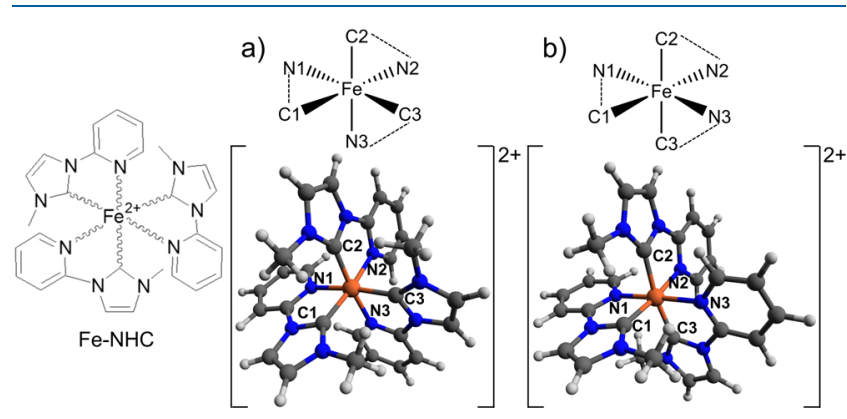

Figure 1. Structure, atom numbering, and ground state optimized geometries of fac-Fe-NHC (a) and mer-Fe-NHC (b).

relevant states are analyzed by molecular modeling using timedependent density functional theory (TD-DFT). Minimum energy path (MEP) calculations of the lowest-lying triplet state are used to find the most favorable path connecting the key structures that mediate the excited-state decay, as well as to estimate the crossing points between the different electronic states partaking in the process. Furthermore, since Fe-NHC can exist in two different geometrical isomers, namely fac and mer, we will for the first time assess the influence of such isomerism in the different decay pathways. A strong influence of the isomer conformation on the excited state lifetimes is predicted.

\section{METHODOLOGY}

Molecular Modeling. The $S_{0}$ and the $Q_{1}$ equilibrium structures have been optimized using the standard density functional theory (DFT)/B3LYP functional given the proved good ability of this hybrid functional to describe related structures. ${ }^{29-31}$ Optimizations and MEP calculations of the $\mathrm{T}_{1}$ state have been conducted using the unrestricted (DFT)/HCTH407 method (hereafter, uDFT/ $\mathrm{HCTH}) .^{32}$ The choice of this exchange correlation functional relies on the good description of the photochemistry of similar iron photoactive compounds previously reported by some authors of this work. ${ }^{11,12,15,16}$
Optimizations of the $S_{1}$ and the $T_{2}$ states have been carried out using the linear-response time-dependent (TD)-HCTH method, making use of the Tamm-Dancoff approximation. ${ }^{33}$ Unless otherwise specified, the standard $6-31+\mathrm{G}(\mathrm{d}, \mathrm{p})$ basis set has been used in all calculations as an adequate compromise between accuracy and computational cost. The solvent effects (acetonitrile) have been included by means of the polarizable continuum model (PCM) in all geometry and MEP optimizations, single-point energy calculations, and spin-orbit coupling (SOC) determinations. The UV-vis spectra of the studied $\mathrm{Fe}$ (II) complexes have been obtained as a convolution of the first 30 singlet excitation energies of 20 different structures obtained by means of a semiclassical Wigner distribution of the $S_{0}$ minima. Gaussian functions with an amplitude of 0.3 have been employed in the convolution. Unless otherwise specified, the GAUSSIAN 09 (D.01 revision) software package ${ }^{34}$ has been used in all calculations.

In order to better define the nature of the involved excited states, their density matrices obtained with the TD-HCTH method have been analyzed in terms of natural transition orbitals (NTOs) ${ }^{35,36}$ obtained as a GAUSSIAN output postprocessing via the Nancy_EX code. $^{36,37}$ For the readers convenience we remind that NTOs, obtained by singular value decomposition of the transition density matrix, may be considered as the best orbitals to describe a given electronic transition, and in contrast to the usual Khon-Sham representation, in most cases only one or two couples of occupied/ virtual orbitals are sufficient to fully account for the electronic density rearrangement. ${ }^{35}$

The decay of the triplet state has been studied by MEP calculations $^{38,39}$ on the $\mathrm{T}_{1}$ state using the uDFT/HCTH method, starting from the $S_{1}$ MLCT minimum (min, see Figure S1). This algorithm provides the lowest-energy path between two points ensuring the connection between them. The procedure is equivalent to the intrinsic reaction coordinate method (IRC), widely used to study adiabatic ground-state chemical reactions. The only difference is found at the starting point: whereas the IRC method uses a transition state structure as the initial geometry, the photochemical MEP starts from a nonequilibrium structure in its electronic excited state. ${ }^{38,40}$ The MEP profiles have been computed using the IRC algorithm as implemented in GAUSSIAN 09. ${ }^{34}$ Single-point calculations on top of the MEP converged structures have been performed using the TDHCTH method to provide all singlet and triplet energies analyzed in this work. On the contrary, the energetics of the quintet $Q$ state along the decay structures have been tracked using the uDFT/HCTH method. For the $\mathrm{Q}$ state, the quadrature convergence method (scf = xqc) of the self-consistent field procedure ${ }^{41}$ has been used in those points with poor convergence when using the GAUSSIAN 09's default scf algorithm. The spin contamination has been carefully analyzed in the Supporting Information and deemed not relevant for the present study.

In both fac-Fe-NHC and mer-Fe-NHC complexes, the high sensitivity of the MEP algorithm to small energy barriers lead to a premature stop of the calculation before reaching the absolute $\mathrm{T}_{1} \min$ geometry. To ensure full relaxation of the state, the last MEP point and the $\mathrm{T}_{1}$ minimum structure (obtained with the GAUSSIAN 09 standard optimization algorithm employing the uDFT/HCTH method) were connected by means of the linear interpolation of the internal coordinates (LIIC) technique, computing a total of 10 intermediate structures (see Figure S1). For the reader's convenience we remind that the LIIC algorithm is simply based on the construction of a generalized coordinate constituted by the weighted average of the geometries of the first and final structure. Note that the same $\mathrm{T}_{1}$ min geometries are obtained if the optimization procedures start from the $S_{1}$ and the $Q_{1}$ minima. The lowest-energy photophysical pathway to populate the $\mathrm{Q}_{1}$ quintet from the $\mathrm{T}_{1} \mathrm{~min}$ structures state has been studied by computing the MEP of the $T_{1}$ state starting from the $\mathrm{Q}_{1}$ min structure, leading the system to evolve toward the $\mathrm{T}_{1} \mathrm{~min}\left({ }^{3} \mathrm{MC}\right)$ structure. In this manner, the $\mathrm{S}_{1} \mathrm{~min}$ (MLCT) and the $\mathrm{Q}_{1}$ min points were connected via MEP calculations. For the present Fe-NHC isomers, the DFT/HCTH energy profiles show no significant differences with respect to the 
curves obtained with the DFT/B3LYP* ${ }^{14,18,19,42}$ and DFT/D2$\mathrm{B}^{2} \mathrm{LYP}^{9,43,44}$ functionals used in previous studies of other iron-based complexes (see Figure S4). The small energy shifts observed are most likely due to the Hartree-Fock exchange included in the DFT/ B3LYP* (15\%) and DFT/D2-B3LYP (20\%) methods and affect equally both $\mathrm{fac}$ - and mer-Fe-NHC isomers.

The SOCs between the singlet and the triplet states at the $S_{0}$ min geometry have been computed using the ADF suite of programs, ${ }^{45-47}$ employing the HCTH functional and the DZP basis set for all atoms expect for the iron atom, described with the TZP basis set. The spinorbit coupling operator has been applied to scalar relativistic TDHCTH calculations by means of perturbation theory. ${ }^{48-50}$ The comparison of both TD-HCTH/6-31+G(d,p) and TD-HCTH/DZP levels of theory, summarized in Tables S1 and S2, shows that both basis sets provide extremely similar descriptions of the studied systems.

Synthesis of fac- and mer-Fe-NHC. Commercially available reagents were used without further purification unless otherwise stated. All solvents were of reagent grade and, when necessary, purified and dried by standard methods. All reactions were routinely checked by TLC analysis on an Alugram SIL G/UV 254 (MachereyNagel) with spots visualized by UV light at 254 and $365 \mathrm{~nm}$. Flash column chromatography was carried out using silica gel from VWR (230-400 mesh). NMR spectra were measured in deuterated solvents on a AC Bruker $400 \mathrm{MHz}$ spectrometer; chemical shifts are reported in parts per million (ppm). All coupling constants $(J)$ are given in $\mathrm{Hz}$. HRMS spectra were recorded on a Bruker micrOTOF-Q ESI spectrometer.

Using standard Schlenk techniques, a $10 \mathrm{~mL}$ Schlenk flask was charged with ligand $\mathbf{L 1} \cdot \mathbf{P F}_{6}{ }^{51}$ (686 $\mathrm{mg}, 2.25 \mathrm{mmol}, 3$ equiv), $\mathrm{FeCl}_{2}$ (95 mg, $0.72 \mathrm{mmol}, 1$ equiv), and dry DMF (4 mL) under argon atmosphere. After dissolution of the starting materials, $t$-BuOK (277 $\mathrm{mg}, 2.47 \mathrm{mmol}, 3.3$ equiv) was introduced and the resulting mixture turned dark-red. The mixture was kept stirring for $1 \mathrm{~h}$ at $\mathrm{rt}$. A solution of diluted $\mathrm{HNO}_{3}$ was added to decrease the $\mathrm{pH}$ to 2 . Then $10 \mathrm{~mL}$ of a saturated solution of $\mathrm{KPF}_{6}$ was added and the precipitate filtered off. The so-obtained solid was purified by chromatography on silica gel using acetone/water $/ \mathrm{KNO}_{3}$ (sat) $(10 / 1 / 0.5)$ as eluent. After evaporation of the acetone in the collected fractions, a solution of saturated $\mathrm{KPF}_{6}$ was added to precipitate the complex. The precipitate was filtered off, washed with deionized water, and dried under vacuum to give a nonseparable $(1: 14)$ mixture of both fac- and mer-isomers (96 $\mathrm{mg}, 25 \%)$ as an orange solid. HRMS (ESI) calcd for $\mathrm{C}_{27} \mathrm{H}_{27} \mathrm{~N}_{9} \mathrm{FeP}_{2} \mathrm{~F}_{12} \quad \mathrm{~m} / z=266.05864\left[\mathrm{M}-2 \mathrm{PF}_{6}\right]^{2+}$. Found: 266.5906. See Supporting Information for NMR signals attribution.

mer-Fe-NHC. ${ }^{1} \mathrm{H}$ NMR (400 MHz, ACN- $\left.d_{3}\right): \delta=8.22(\mathrm{~d}, J=2.2$ $\mathrm{Hz}, 1 \mathrm{H}), 8.15(\mathrm{~d}, J=2.2 \mathrm{~Hz}, 1 \mathrm{H}), 8.11-8.08(\mathrm{~m}, 1 \mathrm{H}), 8.06(\mathrm{~d}, J=2.3$ $\mathrm{Hz}, 1 \mathrm{H}), 7.98(\mathrm{~d}, J=8.3 \mathrm{~Hz}, 1 \mathrm{H}), 7.87-7.80(\mathrm{~m}, 3 \mathrm{H}), 7.69(\mathrm{~d}, J=$ $8.2 \mathrm{~Hz}, 1 \mathrm{H}), 7.66$ (d, $J=8.3 \mathrm{~Hz}, 1 \mathrm{H}), 7.41(\mathrm{~d}, J=2.2 \mathrm{~Hz}, 1 \mathrm{H}), 7.38$ $(\mathrm{d}, J=2.2 \mathrm{~Hz}, 1 \mathrm{H}), 7.32(\mathrm{dd}, J=5.8,0.6 \mathrm{~Hz}, 1 \mathrm{H}), 7.29(\mathrm{td}, J=5.6$, $1.2 \mathrm{~Hz}, 1 \mathrm{H}), 7.19(\mathrm{~d}, J=2.3 \mathrm{~Hz}, 1 \mathrm{H}), 6.91-6.89(\mathrm{~m}, 2 \mathrm{H}), 6.85-6.83$ (dd, $J=5.8,0.7 \mathrm{~Hz}, 1 \mathrm{H}), 3.25(\mathrm{~s}, 3 \mathrm{H}), 2.82(\mathrm{~s}, 3 \mathrm{H}), 2.70(\mathrm{~s}, 3 \mathrm{H})$ ppm. ${ }^{13} \mathrm{C}$ NMR $\left(100 \mathrm{MHz}, \mathrm{ACN}-d_{3}\right): \delta=209.5,205.1,204.5,157.1$, $156.3,155.9,155.7,155.3,152.5,141.5,140.2,139.1,129.0,128.9$, $128.8,124.7,123.4,122.7,118.9,118.0,117.8,113.2,112.4,112.1$, 37.0, 36.0, $35.8 \mathrm{ppm}$.

fac-Fe-NHC. ${ }^{1} \mathrm{H}$ NMR (400 MHz, ACN- $\left.d_{3}\right): \delta=8.11(\mathrm{~d}, J=1.6$ $\mathrm{Hz}, 3 \mathrm{H}), 8.11-8.06(\mathrm{~m}, 3 \mathrm{H}), 7.91(\mathrm{~d}, J=8.3 \mathrm{~Hz}, 3 \mathrm{H}), 7.24-7.21(\mathrm{~m}$, $3 \mathrm{H}), 7.18(\mathrm{~d}, J=2.5 \mathrm{~Hz}, 3 \mathrm{H}), 7.07(\mathrm{dd}, J=5.7,0.7 \mathrm{~Hz}, 3 \mathrm{H}), 2.97$ (s, 9H) ppm. ${ }^{13} \mathrm{C}$ NMR $\left(100 \mathrm{MHz}, \mathrm{ACN}-d_{3}\right): \delta=200.3,151.1,140.7$, 128.5, 124.1, 118.2, 112.9, $36.7 \mathrm{ppm}$.

Steady State Spectroscopy. The UV-vis spectrum was recorded in a $1 \mathrm{~cm}$ path length quartz cell on a LAMBDA 1050 (PerkinElmer) spectrophotometer. The measurements were carried out by using an aerated $10^{-5} \mathrm{M} \mathrm{CH}_{3} \mathrm{CN}$ solution of the $\mathrm{fac} / \mathrm{mer} \mathrm{Fe}-$ $\mathrm{NHC}$ mixture at room temperature.
Scheme 1. Synthesis of the Fe-NHC $\cdot\left(\mathrm{PF}_{6}\right)_{2}$ Complex
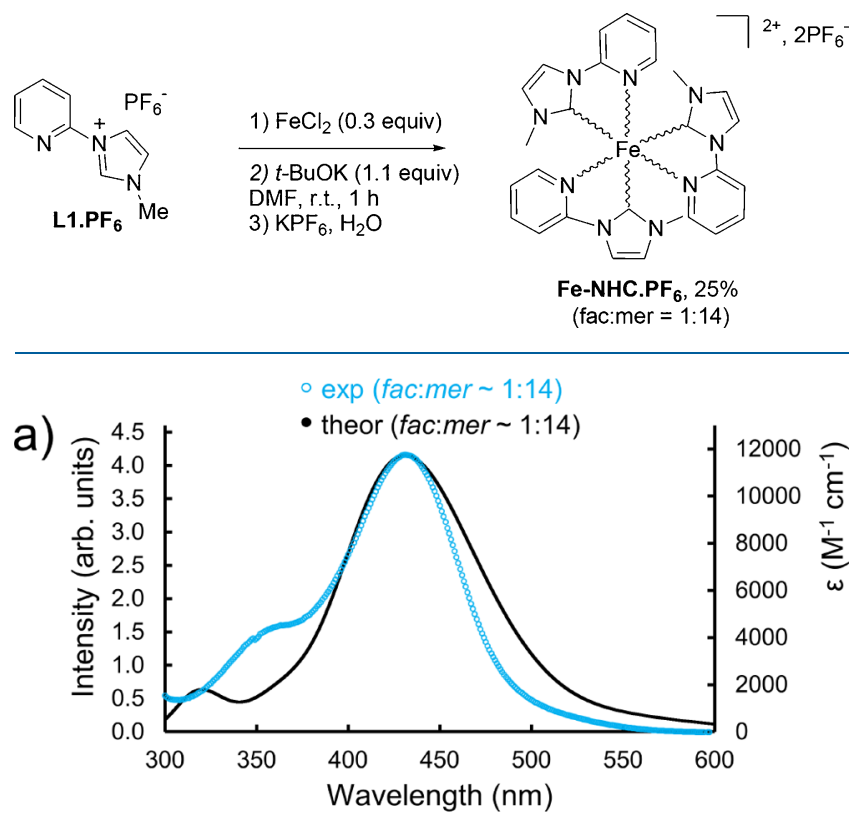

b)
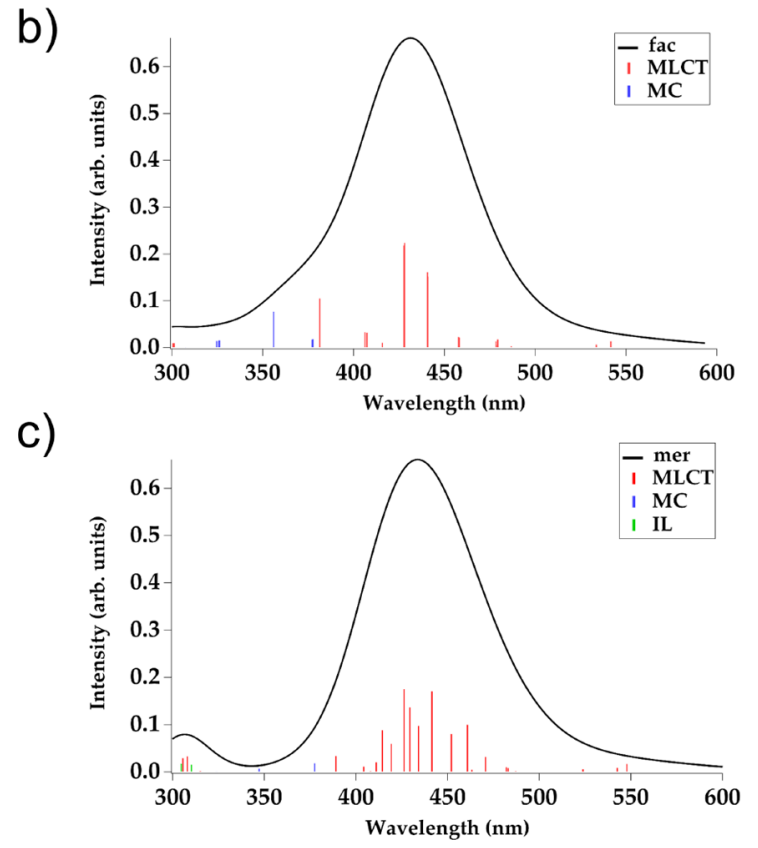

Figure 2. (a) Experimental and simulated absorption spectrum of the fac:mer 1:14 mixture. The theoretical spectrum has been computed at the TD-HCTH/6-31+G(d,p) level of theory using a Wigner distribution of 20 structures. (b) Nature of the excitations of fac$\mathrm{Fe}-\mathrm{NHC}$ at the $\mathrm{S}_{0}$ equilibrium geometry. (c) Nature of the excitations of mer-Fe-NHC at the $S_{0}$ equilibrium geometry. The theoretical excitation energies have been blue-shifted $0.28 \mathrm{eV}$ for an easier visual comparison with the experimental recordings. MLCT = metal-toligand charge transfer, $\mathrm{MC}=$ metal-centered, $\mathrm{IL}=$ intraligand.

\section{RESULTS AND DISCUSSION}

The carbene-precursor 3-methyl-1-(pyridin-2-yl)-1H-imidazolium L1.PF 6 was synthesized according to ref 51 . The subsequent complex synthesis was achieved in DMF solution by in situ generation of the pyridyl/carbene bidentate ligand upon deprotonation of $\mathbf{L} \mathbf{1 .} \mathbf{P F}_{6}$ with $t$-BuOK, in the presence of 


\begin{tabular}{|c|c|c|c|c|c|c|c|}
\hline \multicolumn{4}{|c|}{ fac-Fe-NHC } & \multicolumn{4}{|c|}{ mer-Fe-NHC } \\
\hline State & oNTO & vNTO & Weight $(\%)$ & State & ONTO & vNTO & Weight (\%) \\
\hline $\begin{array}{c}\mathrm{S}_{10} \\
\lambda=440 \mathrm{~nm} \\
(f=0.051)\end{array}$ & & & 45 & $\begin{array}{c}S_{11} \\
\lambda=442 \mathrm{~nm} \\
(f=0.057)\end{array}$ & & & 62 \\
\hline $\begin{array}{c}\mathrm{S}_{10} \\
\lambda=440 \mathrm{~nm} \\
(f=0.051)\end{array}$ & & & 31 & $\begin{array}{c}S_{11} \\
\lambda=442 \mathrm{~nm} \\
(==0.057\end{array}$ & & & 27 \\
\hline $\begin{array}{l}S_{11} \\
\lambda=440 \mathrm{~nm} \\
(f=0.054)\end{array}$ & & & 45 & $\begin{array}{c}\mathrm{S}_{12} \\
\lambda=434 \mathrm{~nm} \\
(f=0.032)\end{array}$ & & & 68 \\
\hline $\begin{aligned} & S_{11} \\
& \lambda=440 \mathrm{~nm} \\
&(f=0.054)\end{aligned}$ & & & 32 & $\begin{array}{c}S_{12} \\
\lambda=434 \mathrm{~nm} \\
\delta=0.032\end{array}$ & & & 19 \\
\hline $\begin{array}{c}\mathrm{S}_{12} \\
\lambda=428 \mathrm{~nm} \\
(f=0.075)\end{array}$ & & & 71 & $\begin{array}{c}S_{13} \\
\lambda=430 \mathrm{~nm} \\
(f=0.045\end{array}$ & & & 85 \\
\hline $\begin{array}{c}\mathrm{S}_{13} \\
\lambda=2427 \mathrm{~nm} \\
(f=0.075)\end{array}$ & & & 73 & $\begin{array}{c}\mathrm{S}_{14} \\
\lambda=430 \mathrm{~nm} \\
(f=0.058)\end{array}$ & & & 75 \\
\hline
\end{tabular}

Figure 3. Occupied or hole (oNTO) and virtual (vNTO) isosurfaces for the bright ${ }^{1}$ MLCT states of fac- (left) and mer- (right) Fe-NHC. The rest of the oNTO $\rightarrow$ vNTO couples (not shown) are of ${ }^{1}$ MLCT nature as well.

$\mathrm{FeCl}_{2}{ }^{12,15}$ A nonseparable fac:mer mixture of complex $\mathrm{Fe}$ $\mathrm{NHC} \cdot\left(\mathrm{PF}_{6}\right)_{2}$ was obtained (Scheme 1).

From the relative integration values, together with the distinct ${ }^{1} \mathrm{H}$ NMR features supported by $2 \mathrm{D}$ experiments (See Supporting Information), an unambiguous NMR characterization can be established for each stereoisomer. By comparison of the normalized integrals $($ per $\mathrm{H})$ of the methyl peaks at ca. 2.5-3.5 ppm on the isolated mixture, a fac:mer ratio of $1: 14$ can be observed.

The spin multiplicity of the ground state for both $\mathrm{fac}$ - and mer-Fe-NHC isomers has been determined by computing the high-spin vs low-spin energy splitting $\left(\Delta E_{\mathrm{HS} / \mathrm{LS}}\right)$ using DFT methods. Bowman et al. ${ }^{31}$ established a clear dependence between the $\Delta E_{\mathrm{HS} / \mathrm{LS}}$ values and the percentage of the Hartree-Fock exchange included in the DFT functional. Therefore, the $\Delta E_{\mathrm{HS} / \mathrm{LS}}$ splitting has been determined using the pure HCTH and the hybrid B3LYP (exchange admixture of $20 \%)$ functionals. With the former functional, $\Delta E_{\mathrm{HS} / \mathrm{LS}}$ is equal to $1.13 \mathrm{eV}(26 \mathrm{kcal} / \mathrm{mol})$ for $\mathrm{fac}$ and to $1.00 \mathrm{eV}(23 \mathrm{kcal} / \mathrm{mol})$ for mer (see Figures 6 and 7). The large positive values indicate that the low spin configuration is favored. Slightly lower splitting values are obtained with the B3LYP functional, in particular $0.91 \mathrm{eV}(21 \mathrm{kcal} / \mathrm{mol})$ for $\mathrm{fac}$ and $0.83 \mathrm{eV}(19 \mathrm{kcal} /$ $\mathrm{mol}$ ) for mer. Thus, the present results unambiguously show that both isomers have singlet ground states.

Steady-State Absorption Spectra. Steady-state experimental and theoretical absorption spectra for $\mathrm{Fe}-\mathrm{NHC}$ are reported in Figure 2. Note that the experimental separation of fac and mer isomers is not trivial. Hence, the recorded spectrum corresponds to a fac:mer 1:14 mixture. One can immediately recognize a good agreement between computational and experimental results. The absorption spectra display two clearly distinct regions in the $300-600 \mathrm{~nm}$ range, namely a broad and intense band centered at $\sim 430 \mathrm{~nm}$ and a less intense signal peaking at $\sim 320 \mathrm{~nm}$ in the calculations, or $360 \mathrm{~nm}$ experimentally (see Figure 2a). Analysis of the nature of the excitations, shown in Figures $2 b$ and $2 c$, indicates that for both isomers the low-energy optical band corresponds to MLCT transitions, whereas the high-energy signal has a marked MC character, in agreement with other $\mathrm{Fe}$ (II) derivatives reported in the literature. $9,18,26,52-54$ This analysis is based on the inspection of the NTOs reported in Figure 3.

Singlet and Triplet Energetics at the Franck-Condon

Region. Previous experimental reports on the photophysics of 


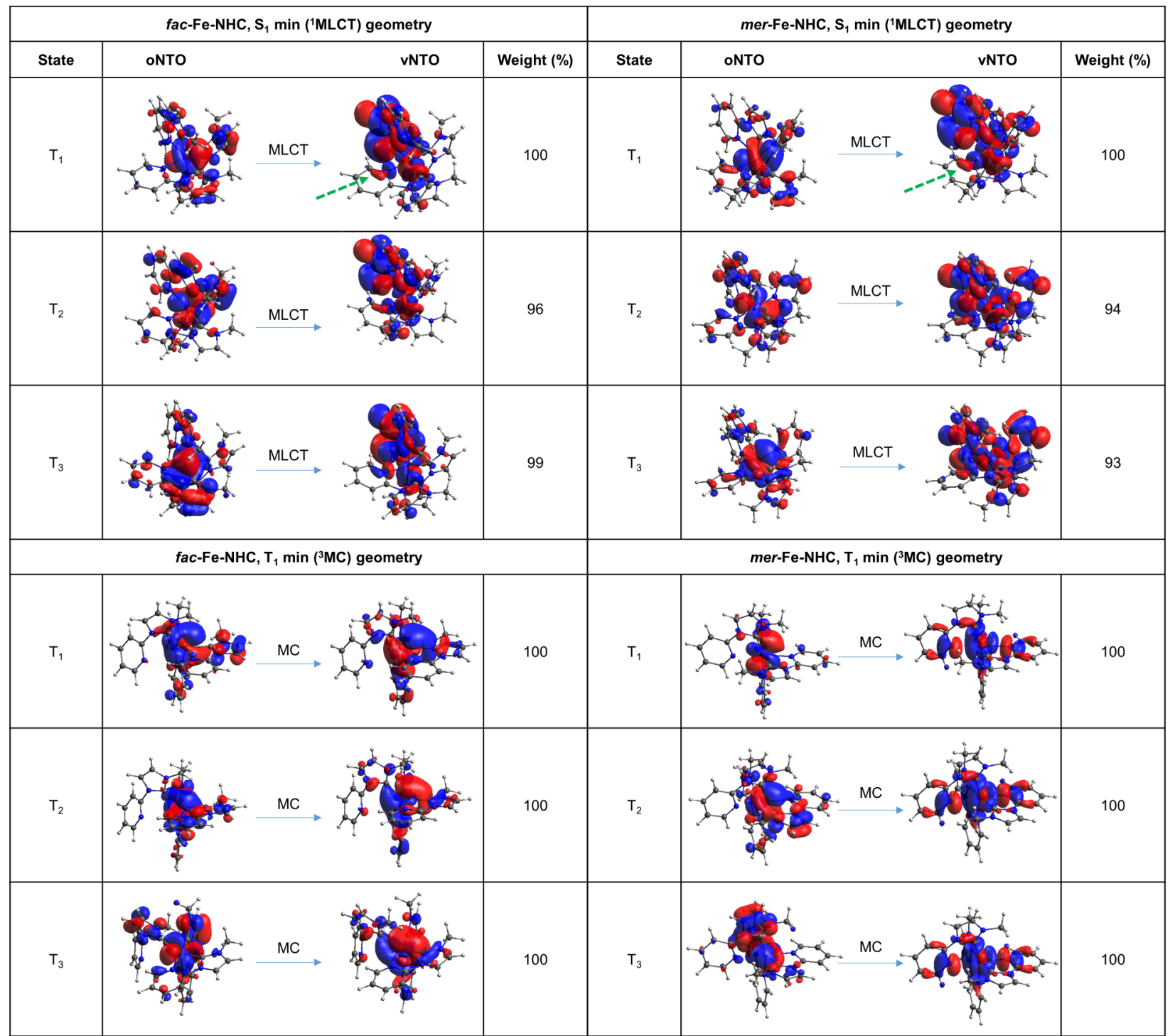

Figure 4. Occupied or hole (oNTO) and virtual (vNTO) isosurfaces for the $\mathrm{T}_{1}, \mathrm{~T}_{2}$, and $\mathrm{T}_{3}$ states of $f a c$ - (left) and mer- (right) Fe-NHC at the $\mathrm{S}_{1}$ $\min \left({ }^{1} \mathrm{MLCT}\right)$ and $\mathrm{T}_{1} \min \left({ }^{3} \mathrm{MC}\right)$ geometries.

related $\mathrm{Fe}(\mathrm{II})$ compounds using time-resolved absorption, ${ }^{18,55}$ fluorescence up-conversion, ${ }^{56}$ and X-ray absorption ${ }^{57-59}$ spectroscopies establish triplet population in less than $\sim 100$ fs. It is thus reasonable to expect that, in the case of the present $\mathrm{fac} / \mathrm{mer} \mathrm{Fe}-\mathrm{NHC}$ complexes, triplet states can be populated in the FC surroundings at ultrafast time scales after excitation to the bright ${ }^{1}$ MLCT states. Figure S5 shows the singlet and triplet energy levels at the FC region. A high density of singlet and triplet states below the bright ${ }^{1} \mathrm{MLCT}$ states $\left(\mathrm{S}_{10}-\mathrm{S}_{13}\right.$ in fac, $S_{11}-S_{14}$ in mer) is expected to mediate the ultrafast internal conversion cascades that relax the hot ${ }^{1,3}$ MLCT states to the lowest-lying ${ }^{1,3} \mathrm{MLCT} \quad \mathrm{S}_{1} / \mathrm{T}_{1}$ states. Such ultrafast intramolecular vibrational-energy redistribution (IVR) has been estimated to occur within $\sim 300 \mathrm{fs}$ in the $\left[\mathrm{Ru}(\mathrm{bpy})_{3}\right]^{2+}$ prototype. $^{60}$

The singlet-triplet SOCs at the $S_{0}$ min geometries of $\mathrm{fac} /$ mer Fe-NHC are reported in Tables S5-S6. The $S_{0}$ equilibrium geometry has been used to compute the singlettriplet SOCs because it is representative of the FranckCondon region. Small nuclear rearrangements can be expected after light absorption given the ultrafast triplet population determined for similar compounds ${ }^{18,55-59}$ and the structural similarity displayed by the $S_{1}\left({ }^{1} \mathrm{MLCT}\right)$ equilibrium structure as compared to the $\mathrm{S}_{0}$ min geometry (see $\mathrm{Fe}-\mathrm{N}$ and $\mathrm{Fe}-\mathrm{C}$ bond distances in Table S7 of the Supporting Information). The energy profiles of the high singlets and triplets displayed in Figure 5 (see below) also suggest that minor structural changes are expected prior to triplet population.

The SOC values are of $\sim 130 \mathrm{~cm}^{-1}$ in the largest cases, significantly smaller than the values exceeding $400 \mathrm{~cm}^{-1}$ reported for heavier metal-based complexes (e.g., ruthenium, ${ }^{61}$ rhenium, ${ }^{62}$ or osmium $^{63}$ ). Therefore, the nonadiabatic ISC efficiency should be significantly lower in the present $\mathrm{fac} / \mathrm{mer}$ Fe-NHC complexes as compared to other species involving heavier metals, pointing to a smaller number of singlet-triplet crossings/recrossings and suggesting a preference for internal conversions either in the singlet or in the triplet manifold. Given the ultrafast triplet population reported experimentally for similar Fe(II) complexes, ${ }^{18,55-59}$ certain preference for the triplet relaxation after initial and fast ISC processes could be expected, even though some singlet relaxation cannot be excluded from our results. As shall be discussed below, the high 
a)

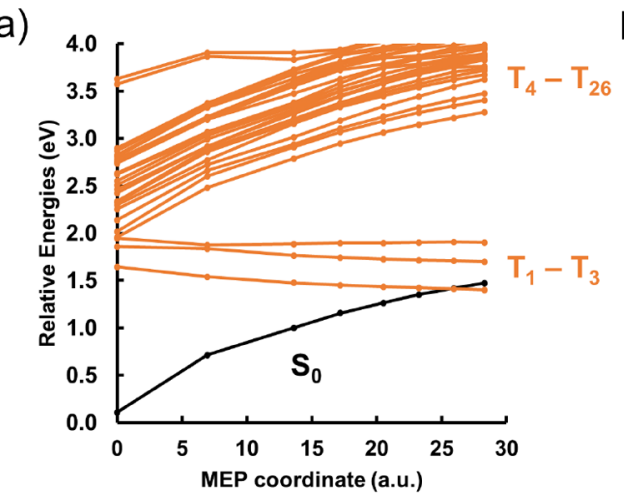

b)

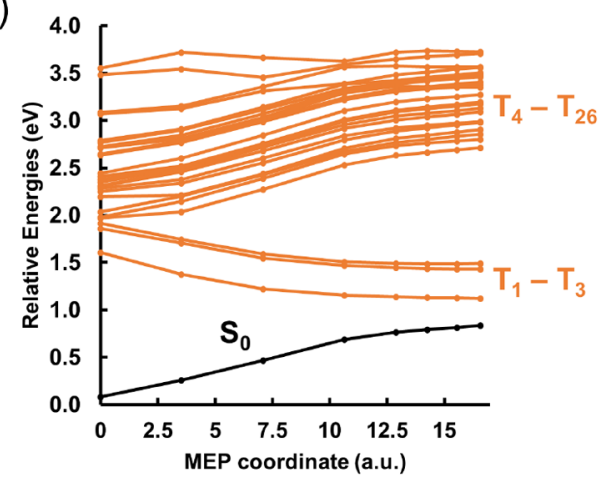

c)

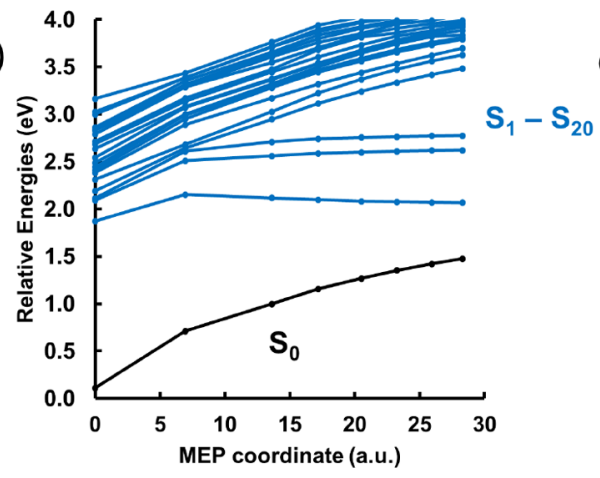

d)

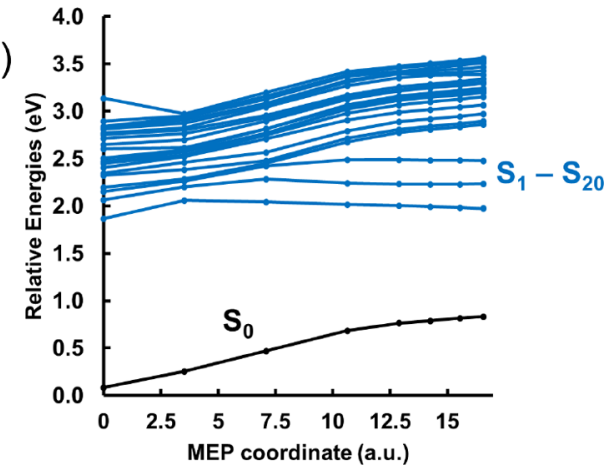

Figure 5. MEP profiles relaxing the $\mathrm{T}_{1}$ state starting from the $\mathrm{S}_{1}$ minimum structures for (a) triplet states of fac-Fe-NHC, (b) triplet states of mer$\mathrm{Fe}-\mathrm{NHC}$, (c) singlet states of fac-Fe-NHC, and (d) singlet states of mer-Fe-NHC.

density of states displayed in Figure S5 suggests that such vibrational cooling can take place without large geometrical deviations from the FC or the $S_{1}{ }^{1}$ MLCT minimum (see also Figure 5 below).

Minimum Energy Path Calculations on the $T_{1}$ Surface. The photochemical evolution of the low-lying triplet states has been studied by means of MEP calculations on the $\mathrm{T}_{1}$ surface. For both $\mathrm{fac} / \mathrm{mer} \mathrm{Fe}-\mathrm{NHC}$ isomers, the starting point for the $T_{1}$ relaxation was the ${ }^{1}$ MLCT $S_{1}$ minimum structures given the absence of well-defined ${ }^{3} \mathrm{MLCT} \mathrm{T}_{1}$ minima. The ${ }^{1}$ MLCT $S_{1}$ minimum structures do not display large geometrical differences with respect to the $\mathrm{FC}$ minima (see the $\mathrm{Fe}-\mathrm{N}$ and the $\mathrm{Fe}-\mathrm{C}$ distances listed in Table S7). All attempts to optimize the ${ }^{3} \mathrm{MLCT} \mathrm{T}_{1}$ state starting from the optimized ${ }^{1}$ MLCT $S_{1}$ minimum lead to the $\mathrm{Fe}-\mathrm{N} 1$ bond dissociation, a process especially suitable to be described via MEP calculations. The reason for the barrierless dissociation might be ascribed to the non-negligible $\mathrm{Fe}-\mathrm{N} \sigma^{*}$ contribution displayed by the virtual NTOs (vNTOs) highlighted by the green dashed arrows in Figure 4 and implying MLCT/MC mixing. The energies of the first 20 singlet states and the first 26 triplet states have been tracked along the $\mathrm{T}_{1}$ MEP coordinate and are shown in Figure 5 . It can be readily seen that whereas the $T_{1}, T_{2}$, and $T_{3}$ states decrease in energy, the $\mathrm{Fe}-\mathrm{N}$ elongations destabilize the rest of the triplet $\left(\mathrm{T}_{4}-\mathrm{T}_{26}\right)$ and all singlet states. These data unambiguously prove that the channel leading to the $\mathrm{Fe}-\mathrm{N} 1$ bond breaking (among other distortions) is not active in the high-lying triplet or singlet states. Globally, this picture supports the vibrational relaxation of the hot ${ }^{1,3}$ MLCT states to the low-lying $\mathrm{T}_{1}, \mathrm{~T}_{2}$, and $\mathrm{T}_{3}$ states in the FC vicinity, and the evolution of the latter states will ultimately govern the nonradiative excited-state decay. The model in which the lowest-lying triplet states governs the excited-state decay has been satisfactorily applied to other $\mathrm{Fe}(\mathrm{II})^{14,18,64,65}$ and $\mathrm{Ru}(\mathrm{II})^{66}$ complexes.

Mechanism for the Excited-State Decay of fac-Fe-

NHC. In order to identify and characterize the key structures that drive the excited-state decay of $f a c-F e-N H C$, the $\mathrm{T}_{1}$ and $\mathrm{T}_{2}$ and the quintet $\mathrm{Q}$ states have been optimized to obtain their corresponding equilibrium geometries. The connectivity between these points is described in detail in the Computational Methods section and Figure S1. The structures are displayed in Figure 6, and the $\mathrm{Fe}-\mathrm{N}$ and $\mathrm{Fe}-\mathrm{C}$ distances are summarized in Table S7. The nuclear coordinate $(\mathrm{NC})=5.0$ corresponds to the $S_{1}$ min geometry, in which the $T_{1}, T_{2}$, and $\mathrm{T}_{3}$ electronic states have MLCT character as identified by inspection of the NTO displayed in Figure 4. The $S_{1}\left({ }^{1}\right.$ MLCT $)$ minimum represents a singlet-triplet crossing (STC) point in which the $S_{1}, T_{1}, T_{2}$, and $T_{3}$ are degenerate or nearly degenerated, enabling effective intersystem crossing (ISC) processes.

Taking into account the partial MLCT/MC mixed character of the triplet states, the evolution of the system either on the $\mathrm{T}_{1}, \mathrm{~T}_{2}$, or $\mathrm{T}_{3}$ surfaces adiabatically increases the metal-centered (MC) nature of the states, leading thus to large $\mathrm{Fe}-\mathrm{N} 1$ bond elongations due to the dissociative character of the MC excitations. The $\mathrm{T}_{1} \min \left({ }^{3} \mathrm{MC}\right)$ point has a large stretch of the $\mathrm{Fe}-\mathrm{N} 1$ bond up to $3.525 \AA$, a distortion that significantly destabilizes the ground state, which becomes higher in energy with respect to the $T_{1}$ state (light-induced spin crossover). Similar elongations of $\mathrm{Fe}-\mathrm{C}$ bonds up to $3.77 \AA$ have been found for the ${ }^{3} \mathrm{MC}$ minimum of related $\mathrm{Fe}(\mathrm{II})$ complexes. ${ }^{18}$ Even though several triplet-quintet crossings (TQCs) involving the $T_{1}, T_{2}, T_{3}$, and $Q_{1}$ states are predicted, the most probable event is the decay of the system to the lowestlying $\mathrm{T}_{1}$ state given the remarkable energy barriers predicted to access the TQC points (see Figure 6), trapping the system in 


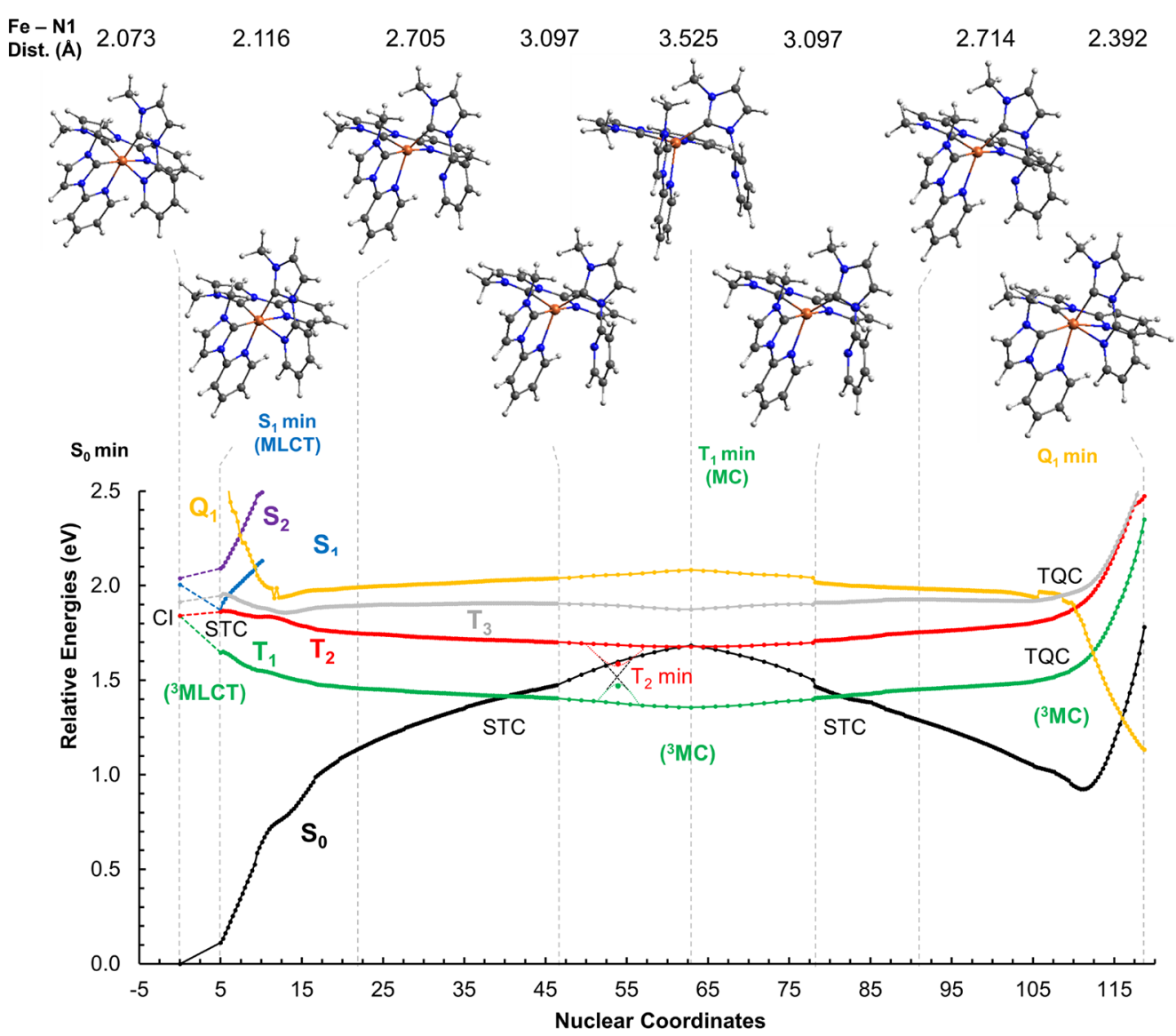

Figure 6. Photochemical landscape of $f a c-F e-N H C$. Arbitrary nuclear coordinate values are used to label the structures obtained along the decay path. The nuclear coordinates $0,5.0,62.9$, and 118.7 correspond to the $S_{0} \min , S_{1} \min \left({ }^{1} \mathrm{MLCT}\right), \mathrm{T}_{1} \min \left({ }^{3} \mathrm{MC}\right)$, and $\mathrm{Q}_{1} \mathrm{~min}$, respectively. $\mathrm{T}_{1}$ and $\mathrm{T}_{2}$ energies at the $\mathrm{T}_{2} \min \left({ }^{3} \mathrm{MC}\right)$ structure (nuclear coordinates $\left.=53.9\right)$ are also shown. $\mathrm{CI}=$ conical intersection, $\mathrm{STC}=$ singlet - triplet crossing, $\mathrm{TQC}=$ triplet - quintet crossing.

the relatively flat $\mathrm{T}_{1} \min \left({ }^{3} \mathrm{MC}\right)$ area. From this region, the main geometrical parameters that relax the $\mathrm{Q}_{\mathrm{J}}$ state are the shortening of the $\mathrm{Fe}-\mathrm{N} 1$ bond and subsequent enlargement of the $\mathrm{Fe}-\mathrm{N} 2$ and $\mathrm{Fe}-\mathrm{N} 3$ distances. The redistribution of the $\mathrm{Fe}-\mathrm{N}$ stretching is consistent with the fact that in the $\mathrm{Q}$ state, two antibonding $\mathrm{e}_{\mathrm{g}}{ }^{*}$ orbitals are singly occupied $(S=2)$, whereas in the triplet manifold the elongation involves only one $\mathrm{Fe}-\mathrm{N}$ bond since only one $\mathrm{e}_{\mathrm{g}}{ }^{*}$ is occupied $(S=1)$. Taking into account that the TQC structures lie below the initial absorption energy, it is reasonable to think that some molecules will have enough kinetic energy to populate the lowest-lying quintet state, although this channel should be considered a minor path given the relative inaccessibility of the TQCs.

The $T_{1}$ state deactivation thus involves the population of the $\mathrm{S}_{0}$ state through the corresponding $\mathrm{S}_{0}-\mathrm{T}_{1}$ STC area. This route is expected to be the most relevant given the accessibility of the STC areas, which lie at much lower energies with respect to the $\mathrm{T}_{1} \min \left({ }^{3} \mathrm{MC}\right)$ structure (see Figure 6). Alternatively, $\mathrm{S}_{0}-\mathrm{T}_{2}$ or $\mathrm{S}_{0}-\mathrm{T}_{3}$ should also be operative. Interestingly, further stretching of the $\mathrm{Fe}-\mathrm{N} 1$ bond on the $\mathrm{T}_{1}$ surface beyond $3.525 \AA$, studied by means of relaxed scan calculations (see Figure S6), indicates negligible changes in the energetics of the low-lying electronic states. Therefore, it can be concluded that, at the $\mathrm{T}_{1} \min \left({ }^{3} \mathrm{MC}\right)$ structure, the $\mathrm{Fe}-\mathrm{N} 1$ bond is completely dissociated.
Mechanism for the Excited-State Decay of mer-FeNHC. The profile of mer-Fe-NHC PESs is displayed in Figure 7. As in the case of $f a c-F e-N H C$, the ultrafast triplet population after light absorption and subsequent decay are expected to ultimately trap the system in the lowest-lying triplet states at the $S_{1}\left({ }^{1} \mathrm{MLCT}\right)$ minimum surroundings (see Figure $5 \mathrm{~b}$ ). The most significant geometrical distortion at this region is the slight elongation of the Fe-N1 bond (see Figure 7 and Table S7). The excited state can evolve on the $T_{1}, T_{2}$, and $T_{3}$ state surfaces toward the $\mathrm{T}_{1}\left({ }^{3} \mathrm{MC}\right)$ minimum, characterized by the $\mathrm{Fe}-\mathrm{N} 1$ enlargement, whereas $\mathrm{Fe}-\mathrm{N} 2$ and $\mathrm{Fe}-\mathrm{N} 3$ bonds are also stretched in a minor extent. As was the case for the fac isomer, the $\mathrm{Q}_{1}$ population channel from the corresponding TQC regions is possible, but it should be considered a far less favorable route with respect to decay to the $T_{1}$ state due to the important energy barriers predicted for these paths. Interestingly, the lowest-energy point on the $T_{1}$ surface is found at the $\mathrm{Fe}-\mathrm{N} 1$ distance of $2.781 \AA$, whereas the same point in the case of the $f a c$ isomer corresponds to a distance of $3.525 \AA$. The enlargement of the $\mathrm{Fe}-\mathrm{N} 1$ bond distance of mer-Fe-NHC beyond 2.781 Å gives rise to a quasi-planar $\mathrm{T}_{1}$ PES (see Figure S7), revealing that similar geometrical distortions implying $\mathrm{Fe}-\mathrm{N} 1$ stretches larger than $3.0 \AA$ can take place during the excited-state decay of both $f a c$ and mer isomers.

Indeed, the most striking result is that the vibrational relaxation energy along the $\mathrm{T}_{1}, \mathrm{~T}_{2}$, and $\mathrm{T}_{3}$ surfaces is significantly larger for mer-Fe-NHC than for fac-Fe-NHC, 


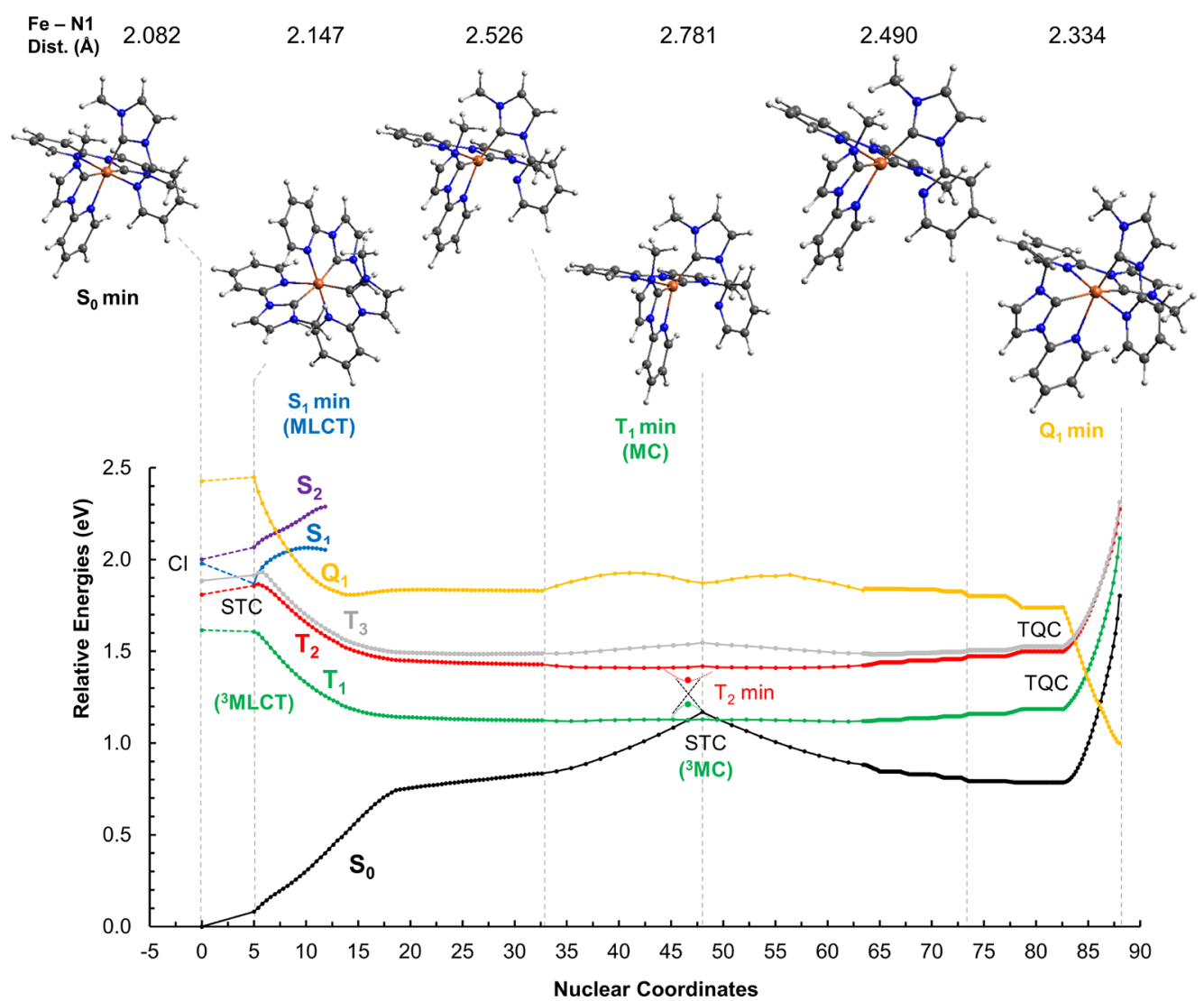

Figure 7. Photochemical landscape of mer-Fe-NHC. Arbitrary nuclear coordinate values are used to label the structures obtained along the decay path. The nuclear coordinates $0,5.0,48.0$, and 88.0 correspond to the $S_{0} \min , S_{1} \min \left({ }^{1} \mathrm{MLCT}\right), \mathrm{T}_{1} \min \left({ }^{3} \mathrm{MC}\right)$, and $\mathrm{Q}_{1} \mathrm{~min}$, respectively. $\mathrm{T}_{1}$ and $\mathrm{T}_{2}$ energies at the $\mathrm{T}_{2} \min \left({ }^{3} \mathrm{MC}\right)$ structure (nuclear coordinates $\left.=46.6\right)$ are also shown. $\mathrm{CI}=$ conical intersection, $\mathrm{STC}=$ singlet - triplet crossing, $\mathrm{TQC}=$ triplet - quintet crossing.

since the triplet surfaces for the latter are more planar. It is worth noting the difference in the relative energies (with respect to the ground state at its equilibrium geometry) of the $\mathrm{T}_{1} \min \left({ }^{3} \mathrm{MC}\right)$ for both isomers. In particular, this point lies at $1.36 \mathrm{eV}$ for $\mathrm{fac}$-Fe-NHC (see Figure 6), whereas it is placed at $1.13 \mathrm{eV}$ for mer-Fe-NHC (see Figure 7), indicating a larger vibrational relaxation for the latter isomer. Indeed, for related cyclometalated $\mathrm{Fe}(\mathrm{II})$ complexes with triplet excited-state lifetime differences of several picoseconds, it has been previously found that the relative positions of their respective ${ }^{3} \mathrm{MC}$ minima differ by some tenths of $\mathrm{eV}$, associating faster triplet decays to lower ${ }^{3} \mathrm{MC}$ energies. ${ }^{11,12,15}$ Therefore, the present results on the triplet PESs point to a faster triplet decay of $m e r-\mathrm{Fe}-\mathrm{NHC}$ with respect to the fac-Fe-NHC isomer. This result may be the first indication of the subtle control on the photophysics and triplet state lifetime by geometrical isomerism in $\mathrm{Fe}(\mathrm{II})$ octahedral complexes.

\section{CONCLUSIONS}

In this contribution, we have applied a combination of state-ofthe-art excited state methodologies together with experimental characterization to achieve a proper rationalization of the photophysical behavior of iron(II)-based organometallic compounds specifically designed for exhibiting increased excited state lifetimes in view of potential applications in optoelectronic devices. Indeed, our results confirm that the excited states evolution taking place into organometallic compounds presents a much higher degree of complexity than the corresponding phenomena happening in organic chromophores. This aspect may lead to truly unexpected and complex photophysical and photochemical behavior and is due to a high density of states, the presence of different competitive deactivation channels, as well as relativistic effects, such as high SOC, that may favor spin-forbidden channels. In particular, we have shown that the PESs of iron(II)-based compounds should be properly and entirely described in order to achieve a complete rationalization of the involved phenomena to properly take into account all the possible deactivation channels. Indeed, an oversimplified, though useful, ligandfield splitting computation and/or determination of single minima points in the PESs is not sufficient to provide all the subtle details that may instead be crucial in dictating the photophysical behavior of the involved compounds, as also pointed out by the work of different authors. ${ }^{28}$

As a most striking example, the proper use of molecular modeling, and in particular the full description of the MEPs, has allowed unraveling of the key differences in the PES topologies of the two isomers, which can be related to a strong effect on the excited state lifetimes. Even though differences in $\mathrm{fac}$ and mer optoelectronic properties have been reported for organometallic compounds based on other metals, ${ }^{67-71}$ this is, to the best of our knowledge, the first prediction of such a fundamental phenomenon for iron complexes. Experimental studies, such as pump-probe spectroscopy on model systems allowing confirmation of our findings, are currently being performed. Moreover, the analysis of the MEP has clearly shown that the triplet relaxation will proceed through the $\mathrm{Fe}-$ $\mathrm{N}$ bond elongation. Indeed, the rather impressive bond 
elongation as well as the difference in its behavior between the two isomers point to such a coordinate as the weak point clearly driving the deactivation of the MLCT states. Hence, this finding may guide the development of iron(II) complexes with longer living MLCT states by blocking such coordinate via geometrical constraints or by reducing the number of ironnitrogen coordination points. Finally, our exploration of the iron(II)-based complex's PES points to a negligible role of the spin-crossover phenomena since the population of the quintet states from the triplet manifold should require overcoming significant energy barriers.

In future works, we plan from the one side to expand the present study performing pump-probe experiments to unravel lifetime differences between the two isomers, as predicted by the different topology of the PES. On the other hand, the use of nonadiabatic dynamics can be suggested in order to dynamically follow the relaxation processes taking place after excitations and, thus, offer a one-to-one mapping between experiment and molecular modeling.

\section{ASSOCIATED CONTENT}

\section{S Supporting Information}

The Supporting Information is available free of charge on the ACS Publications website at DOI: 10.1021/acs.inorgchem.8b01695.

NMR spectra of the Fe-NHC isomers, elongations of the $\mathrm{Fe}-\mathrm{N} 1$ bonds, $\mathrm{Fe}-\mathrm{C}$ and $\mathrm{Fe}-\mathrm{N}$ bond lengths, SOC values, spin contamination analysis, DFT/B3LYP* and DFT/D2-B3LYP MEP profiles, and Cartesian coordinates of the studied structures (PDF)

\section{AUTHOR INFORMATION}

\section{Corresponding Authors}

*Antonio Monari e-mail: Antonio.Monari@univ-lorraine.fr.

*Antonio Francés-Monerris e-mail: Antonio.Frances@univlorraine.fr.

\section{ORCID}

Antonio Francés-Monerris: 0000-0001-8232-4989

Antonio Monari: 0000-0001-9464-1463

\section{Notes}

The authors declare no competing financial interest.

\section{ACKNOWLEDGMENTS}

The work has been funded by the ANR (French national research agency) PhotIron project ANR-16-CE07-0013. A.F.M. also acknowledges the support of the CTQ2017-87054-C22-P project of the Ministerio de Economia y Competitividad and is grateful to Dr. Marta E. Alberto for the fruitful scientific discussions.

\section{REFERENCES}

(1) O’Regan, B.; Grätzel, M. A Low-Cost, High-Efficiency Solar Cell Based on Dye-Sensitized Colloidal TiO2 Films. Nature 1991, 353, 737-740.

(2) Browne, W. R.; Feringa, B. L. Making Molecular Machines Work. Nat. Nanotechnol. 2006, 1, 25-35.

(3) Colasson, B.; Credi, A.; Ragazzon, G. Light-Driven Molecular Machines Based on Ruthenium(II) Polypyridine Complexes: Strategies and Recent Advances. Coord. Chem. Rev. 2016, 325, $125-134$.
(4) Kalinowski, J.; Fattori, V.; Cocchi, M.; Williams, J. A. G. LightEmitting Devices Based on Organometallic Platinum Complexes as Emitters. Coord. Chem. Rev. 2011, 255, 2401-2425.

(5) Clark, C. D.; Hoffman, M. Z.; Rillema, D. P.; Mulazzani, Q. G. Photophysics of Ruthenium(II) Complexes with 2-(2'-Pyridyl)Pyrimidine and 2,2'-Bipyridine Ligands in Fluid Solution. J. Photochem. Photobiol., A 1997, 110, 285-290.

(6) Frischmann, P. D.; Mahata, K.; Würthner, F.; Lewis, N. S.; Blankenship, R. E.; Tiede, D. M.; Barber, J.; Brudvig, G. W.; Fleming, G.; Ghirardi, M.; et al. Powering the Future of Molecular Artificial Photosynthesis with Light-Harvesting Metallosupramolecular Dye Assemblies. Chem. Soc. Rev. 2013, 42, 1847-1870.

(7) Tian, H.; Boschloo, G.; Hagfeldt, A. Molecular Devices for Solar Energy Conversion and Storage, 1st ed.; Springer Nature Singapore, 2018.

(8) Lees, A. J.; Long, C. Photophysics of Organometallics. Top. Organomet. Chem. 2010, 29, 37-71.

(9) Mukherjee, S.; Torres, D. E.; Jakubikova, E. HOMO Inversion as a Strategy for Improving the Light-Absorption Properties of $\mathrm{Fe}(\mathrm{II})$ Chromophores. Chem. Sci. 2017, 8, 8115-8126.

(10) Jakubikova, E.; Bowman, D. N. Fe(II)-Polypyridines as Chromophores in Dye-Sensitized Solar Cells: A Computational Perspective. Acc. Chem. Res. 2015, 48, 1441-1449.

(11) Duchanois, T.; Liu, L.; Pastore, M.; Monari, A.; Cebrián, C.; Trolez, Y.; Darari, M.; Magra, K.; Francés-Monerris, A.; Domenichini, E.; et al. NHC-Based Iron Sensitizers for DSSCs. Inorganics 2018, 6, 63.

(12) Liu, L.; Duchanois, T.; Etienne, T.; Monari, A.; Beley, M.; Assfeld, X.; Haacke, S.; Gros, P. C. A New Record Excited State ${ }^{3}$ MLCT Lifetime for Metalorganic Iron(II) Complexes. Phys. Chem. Chem. Phys. 2016, 18, 12550-12556.

(13) Ericson, F.; Honarfar, A.; Prakash, O.; Tatsuno, H.; Fredin, L. A.; Handrup, K.; Chabera, P.; Gordivska, O.; Kjær, K. S.; Liu, Y.; et al. Electronic Structure and Excited State Properties of Iron Carbene Photosensitizers - A Combined X-Ray Absorption and Quantum Chemical Investigation. Chem. Phys. Lett. 2017, 683, 559-566.

(14) Dixon, I. M.; Alary, F.; Boggio-Pasqua, M.; Heully, J.-L. Reversing the Relative ${ }^{3}$ MLCT $-{ }^{3} \mathrm{MC}$ Order in $\mathrm{Fe}(\mathrm{II})$ Complexes Using Cyclometallating Ligands: A Computational Study Aiming at Luminescent Fe(II) Complexes. Dalt. Trans. 2015, 44, 13498-13503.

(15) Duchanois, T.; Etienne, T.; Cebrián, C.; Liu, L.; Monari, A.; Beley, M.; Assfeld, X.; Haacke, S.; Gros, P. C. An Iron-Based Photosensitizer with Extended Excited-State Lifetime: Photophysical and Photovoltaic Properties. Eur. J. Inorg. Chem. 2015, 2469-2477.

(16) Duchanois, T.; Etienne, T.; Beley, M.; Assfeld, X.; Perpète, E. A.; Monari, A.; Gros, P. C. Heteroleptic Pyridyl-Carbene Iron Complexes with Tuneable Electronic Properties. Eur. J. Inorg. Chem. 2014, 3747-3753.

(17) Pastore, M.; Duchanois, T.; Liu, L.; Monari, A.; Assfeld, X.; Haacke, S.; Gros, P. C. Interfacial Charge Separation and Photovoltaic Efficiency in Fe(II)-Carbene Sensitized Solar Cells. Phys. Chem. Chem. Phys. 2016, 18, 28069-28081.

(18) Chábera, P.; Kjaer, K. S.; Prakash, O.; Honarfar, A.; Liu, Y.; Fredin, L. A.; Harlang, T. C. B.; Lidin, S.; Uhlig, J.; Sundström, V.; et al. $\mathrm{Fe}^{\mathrm{II}}$ Hexa N-Heterocyclic Carbene Complex with a 528 ps Metal-to-Ligand Charge-Transfer Excited-State Lifetime. J. Phys. Chem. Lett. 2018, 9, 459-463.

(19) Fredin, L. A.; Pápai, M.; Rozsályi, E.; Vankó, G.; Wärnmark, K.; Sundström, V.; Persson, P. Exceptional Excited-State Lifetime of an Iron(II)- N -Heterocyclic Carbene Complex Explained. J. Phys. Chem. Lett. 2014, 5, 2066-2071.

(20) Zhang, W.; Kjær, K. S.; Alonso-Mori, R.; Bergmann, U.; Chollet, M.; Fredin, L. A.; Hadt, R. G.; Hartsock, R. W.; Harlang, T.; Kroll, T.; et al. Manipulating Charge Transfer Excited State Relaxation and Spin Crossover in Iron Coordination Complexes with Ligand Substitution. Chem. Sci. 2017, 8, 515-523.

(21) Fatur, S. M.; Shepard, S. G.; Higgins, R. F.; Shores, M. P.; Damrauer, N. H. A Synthetically Tunable System to Control MLCT 
Excited-State Lifetimes and Spin States in Iron(II) Polypyridines. J. Am. Chem. Soc. 2017, 139, 4493-4505.

(22) Kjær, K. S.; Zhang, W.; Alonso-Mori, R.; Bergmann, U.; Chollet, M.; Hadt, R. G.; Hartsock, R. W.; Harlang, T.; Kroll, T.; Kubiček, K.; et al. Ligand Manipulation of Charge Transfer Excited State Relaxation and Spin Crossover in $\left[\mathrm{Fe}\left(2,2^{\prime} \text {-Bipyridine }\right)_{2}(\mathrm{CN})_{2}\right]$. Struct. Dyn. 2017, 4, 044030.

(23) Shepard, S. G.; Fatur, S. M.; Rappé, A. K.; Damrauer, N. H. Highly Strained Iron(II) Polypyridines: Exploiting the Quintet Manifold to Extend the Lifetime of MLCT Excited States. J. Am. Chem. Soc. 2016, 138, 2949-2952.

(24) Sousa, C.; De Graaf, C.; Rudavskyi, A.; Broer, R.; Tatchen, J.; Etinski, M.; Marian, C. M. Ultrafast Deactivation Mechanism of the Excited Singlet in the Light-Induced Spin Crossover of $[\mathrm{Fe}(2,2$ 'Bipyridine) $\left.{ }_{3}\right]^{2+}$. Chem. - Eur. J. 2013, 19, 17541-17551.

(25) De Graaf, C.; Sousa, C. On the Role of the Metal-to-Ligand Charge Transfer States in the Light-Induced Spin Crossover in Fe (Bpy) $)_{3}$. Int. J. Quantum Chem. 2011, 111, 3385-3393.

(26) Pápai, M.; Vankó, G.; De Graaf, C.; Rozgonyi, T. Theoretical Investigation of the Electronic Structure of $\mathrm{Fe}$ (II) Complexes at SpinState Transitions. J. Chem. Theory Comput. 2013, 9, 509-519.

(27) Nance, J.; Bowman, D. N.; Mukherjee, S.; Kelley, C. T.; Jakubikova, E. Insights into the Spin-State Transitions in [Fe$\left.(\mathrm{Tpy})^{2}\right]^{2}+$ Importance of the Terpyridine Rocking Motion. Inorg. Chem. 2015, 54, 11259-11268.

(28) Ashley, D. C.; Jakubikova, E. Ironing out the Photochemical and Spin-Crossover Behavior of $\mathrm{Fe}(\mathrm{II})$ Coordination Compounds with Computational Chemistry. Coord. Chem. Rev. 2017, 337, 97111.

(29) Verma, P.; Varga, Z.; Klein, J. E. M. N.; Cramer, C. J.; Que, L.; Truhlar, D. G. Assessment of Electronic Structure Methods for the Determination of the Ground Spin States of $\mathrm{Fe}(\mathrm{II}), \mathrm{Fe}(\mathrm{III})$ and Fe(IV) Complexes. Phys. Chem. Chem. Phys. 2017, 19, 13049-13069.

(30) Alexander, B. D.; Dines, T. J.; Longhurst, R. W. DFT Calculations of the Structures and Vibrational Spectra of the $\left[\mathrm{Fe}(\mathrm{Bpy})_{3}\right]^{2+}$ and $\left[\mathrm{Ru}(\text { Bpy })_{3}\right]^{2+}$ Complexes. Chem. Phys. 2008, 352, 19-27.

(31) Bowman, D. N.; Jakubikova, E. Low-Spin versus High-Spin Ground State in Pseudo-Octahedral Iron Complexes. Inorg. Chem. 2012, 51, 6011-6019.

(32) Boese, A. D.; Handy, N. C. A New Parametrization of Exchange-correlation Generalized Gradient Approximation Functionals. J. Chem. Phys. 2001, 114, 5497-5503.

(33) Hirata, S.; Head-Gordon, M. Time-Dependent Density Functional Theory within the Tamm-Dancoff Approximation. Chem. Phys. Lett. 1999, 314, 291-299.

(34) Frisch, M. J.; Trucks, G. W.; Schlegel, H. B.; Scuseria, G. E.; Robb, M. A.; Cheeseman, J. R.; Scalmani, G.; Barone, V.; Mennucci, B.; Petersson, G. A.; et al. Gaussian 09 Revision D.01; Gaussian Inc.: Wallingford, CT, 2010.

(35) Martin, R. L. Natural Transition Orbitals. J. Chem. Phys. 2003, $118,4775-4777$.

(36) Etienne, T.; Assfeld, X.; Monari, A. Toward a Quantitative Assessment of Electronic Transitions' Charge-Transfer Character. J. Chem. Theory Comput. 2014, 10, 3896-3905.

(37) Etienne, T.; Assfeld, X.; Monari, A. New Insight into the Topology of Excited States through Detachment/Attachment Density Matrices-Based Centroids of Charge. J. Chem. Theory Comput. 2014, 10, 3906-3914.

(38) De Vico, L.; Olivucci, M.; Lindh, R. New General Tools for Constrained Geometry Optimizations. J. Chem. Theory Comput. 2005, 1, 1029-1037.

(39) Schlegel, B. H. Exploring Potential Energy Surfaces for Chemical Reactions: An Overview of Some Practical Methods. J. Comput. Chem. 2003, 24, 1514-1527.

(40) Serrano-Pérez, J. J.; Serrano-Andrés, L. Calculation of Excited States: Molecular Photophysics and Photochemistry on Display. In Handbook of Computational Chemistry; Leszczynski, J., Ed.; SpringerVerlag: Berlin, 2012; pp 483-560.
(41) Bacskay, G. B. A Quadratically Convergent Hartree-Fock (QC-SCF) Method. Application to Closed Shell Systems. Chem. Phys. 1981, 61, 385-404.

(42) Kepp, K. P. Theoretical Study of Spin Crossover in 30 Iron Complexes. Inorg. Chem. 2016, 55, 2717-2727.

(43) Bowman, D. N.; Bondarev, A.; Mukherjee, S.; Jakubikova, E. Tuning the Electronic Structure of Fe(II) Polypyridines via Donor Atom and Ligand Scaffold Modifications: A Computational Study. Inorg. Chem. 2015, 54, 8786-8793.

(44) Bedford, R. B.; Brenner, P. B.; Carter, E.; Clifton, J.; Cogswell, P. M.; Gower, N. J.; Haddow, M. F.; Harvey, J. N.; Kehl, J. A.; Murphy, D. M.; et al. Iron Phosphine Catalyzed Cross-Coupling of Tetraorganoborates and Related Group 13 Nucleophiles with Alkyl Halides. Organometallics 2014, 33, 5767-5780.

(45) Baerends, E. J.; Ziegler, T.; Atkins, A. J.; Autschbach, J.; Bashford, D.; Baseggio, O.; Bérces, A.; Bickelhaupt, F. M.; Bo, C.; Boerritger, P. M.; et al. ADF; SCM, Theoretical Chemistry, Vrije Universiteit: Amsterdam, The Netherlands, 2017, https://www.scm. com.

(46) te Velde, G.; Bickelhaupt, F. M.; Baerends, E. J.; Fonseca Guerra, C.; van Gisbergen, S. J. A.; Snijders, J. G.; Ziegler, T. Chemistry with ADF. J. Comput. Chem. 2001, 22, 931-967.

(47) Guerra, C. F.; Snijders, J. G.; te Velde, G.; Baerends, E. J. Towards an Order-N DFT Method. Theor. Chem. Acc. 1998, 99, 391403.

(48) Van Lenth, E.; Baerends, E. J.; Snijders, J. G. Relativistic Regular Two-component Hamiltonians. J. Chem. Phys. 1993, 99, 4597-4610.

(49) van Lenthe, E.; Baerends, E. J.; Snijders, J. G. Relativistic Total Energy Using Regular Approximations. J. Chem. Phys. 1994, 101, 9783-9792.

(50) van Lenthe, E.; Ehlers, A.; Baerends, E.-J. Geometry Optimizations in the Zero Order Regular Approximation for Relativistic Effects. J. Chem. Phys. 1999, 110, 8943-8953.

(51) Barbante, G. J.; Francis, P. S.; Hogan, C. F.; Kheradmand, P. R.; Wilson, D. J. D.; Barnard, P. J. Electrochemiluminescent Ruthenium(II) N-Heterocyclic Carbene Complexes: A Combined Experimental and Theoretical Study. Inorg. Chem. 2013, 52, 7448-7459.

(52) Zimmer, P.; Burkhardt, L.; Friedrich, A.; Steube, J.; Neuba, A.; Schepper, R.; Müller, P.; Flörke, U.; Huber, M.; Lochbrunner, S.; et al. The Connection between NHC Ligand Count and Photophysical Properties in Fe(II) Photosensitizers: An Experimental Study. Inorg. Chem. 2018, 57, 360-373.

(53) Vankó, G.; Bordage, A.; Pápai, M.; Haldrup, K.; Glatzel, P.; March, A. M.; Doumy, G.; Britz, A.; Galler, A.; Assefa, T.; et al. Detailed Characterization of a Nanosecond-Lived Excited State: XRay and Theoretical Investigation of the Quintet State in Photoexcited $\left[\mathrm{Fe}(\text { terpy })^{2] 2+}\right.$. J. Phys. Chem. C 2015, 119, 5888-5902.

(54) Das, A. K.; Solomon, R. V.; Hofmann, F.; Meuwly, M. InnerShell Water Rearrangement Following Photoexcitation of Tris $\left(2,2^{\prime}\right.$ bipyridine)iron(II). J. Phys. Chem. B 2016, 120, 206-216.

(55) Monat, J. E.; McCusker, J. K. Femtosecond Excited-State Dynamics of an Iron(II) Polypyridyl Solar Cell Sensitizer Model. J. Am. Chem. Soc. 2000, 122, 4092-4097.

(56) Gawelda, W.; Cannizzo, A.; Pham, V.-T.; van Mourik, F.; Bressler, C.; Chergui, M. Ultrafast Nonadiabatic Dynamics of $\left[\mathrm{Fe}^{\mathrm{II}}(\mathrm{Bpy})_{3}\right]^{2+}$ in Solution. J. Am. Chem. Soc. 2007, 129, 8199-8206.

(57) Bressler, C.; Milne, C.; Pham, V.-T.; ElNahhas, A.; van der Veen, R. M.; Gawelda, W.; Johnson, S.; Beaud, P.; Grolimund, D.; Kaiser, M.; et al. Femtosecond XANES Study of the Light-Induced Spin Crossover Dynamics in an Iron(II) Complex. Science 2009, 323, 489-492.

(58) Zhang, W.; Alonso-Mori, R.; Bergmann, U.; Bressler, C.; Chollet, M.; Galler, A.; Gawelda, W.; Hadt, R. G.; Hartsock, R. W.; Kroll, T.; et al. Tracking Excited-State Charge and Spin Dynamics in Iron Coordination Complexes. Nature 2014, 509, 345.

(59) Kjaer, K. S.; Kunnus, K.; Harlang, T. C. B.; Van Driel, T. B.; Ledbetter, K.; Hartsock, R. W.; Reinhard, M. E.; Koroidov, S.; Li, L.; Laursen, M. G.; et al. Solvent Control of Charge Transfer Excited 
State Relaxation Pathways in $\left[\mathrm{Fe}\left(2,2^{\prime} \text {-bipyridine }\right)(\mathrm{CN})_{4}\right]^{2-}$. Phys. Chem. Chem. Phys. 2018, 20, 4238-4249.

(60) Cannizzo, A.; van Mourik, F.; Gawelda, W.; Zgrablic, G.; Bressler, C.; Chergui, M. Broadband Femtosecond Fluorescence Spectroscopy of $\left[\mathrm{Ru}(\mathrm{bpy})_{3}\right]^{2+}$. Angew. Chem. 2006, 118, 3246-3248.

(61) Alberto, M. E.; Russo, N.; Adamo, C. Synergistic Effects of Metals in a Promising $\mathrm{Ru}(\mathrm{II})-\mathrm{Pt}(\mathrm{II})$ Assembly for a Combined Anticancer Approach: Theoretical Exploration of the Photophysical Properties. Chem. - Eur. J. 2016, 22, 9162-9168.

(62) Gourlaouen, C.; Eng, J.; Otsuka, M.; Gindensperger, E.; Daniel, C. Quantum Chemical Interpretation of Ultrafast Luminescence Decay and Intersystem Crossings in Rhenium(I) Carbonyl Bipyridine Complexes. J. Chem. Theory Comput. 2015, 11, 99-110.

(63) Yu-Tzu Li, E.; Jiang, T.-Y.; Chi, Y.; Chou, P.-T. SemiQuantitative Assessment of the Intersystem Crossing Rate: An Extension of the El-Sayed Rule to the Emissive Transition Metal Complexes. Phys. Chem. Chem. Phys. 2014, 16, 26184-26192.

(64) Liu, Y.; Kjær, K. S.; Fredin, L. A.; Chábera, P.; Harlang, T.; Canton, S. E.; Lidin, S.; Zhang, J.; Lomoth, R.; Bergquist, K.; et al. A Heteroleptic Ferrous Complex with Mesoionic Bis(1,2,3-triazol-5ylidene) Ligands: Taming the MLCT Excited State of Iron(II). Chem. - Eur. J. 2015, 21, 3628-3639.

(65) Dixon, I. M.; Alary, F.; Boggio-Pasqua, M.; Heully, J.-L. The $\left(\mathrm{N}_{4} \mathrm{C}_{2}\right)^{2-}$ Donor Set as Promising Motif for Bis(Tridentate) Iron(II) Photoactive Compounds. Inorg. Chem. 2013, 52, 13369-13374.

(66) Sun, Q.; Dereka, B.; Vauthey, E.; Lawson Daku, L. M.; Hauser, A. Ultrafast Transient IR Spectroscopy and DFT Calculations of Ruthenium(II) Polypyridyl Complexes. Chem. Sci. 2017, 8, 223-230.

(67) Tamayo, A. B.; Alleyne, B. D.; Djurovich, P. I.; Lamansky, S.; Tsyba, I.; Ho, N. N.; Bau, R.; Thompson, M. E. Synthesis and Characterization of Facial and Meridional Tris-Cyclometalated Iridium(III) Complexes. J. Am. Chem. Soc. 2003, 125, 7377-7387.

(68) Cho, Y.-J.; Kim, S.-Y.; Kim, J.-H.; Lee, J.; Cho, D. W.; Yi, S.; Son, H.-J.; Han, W.-S.; Kang, S. O. Probing Photophysical Properties of Isomeric N-Heterocyclic Carbene $\operatorname{Ir}(\mathrm{III})$ Complexes and Their Applications to Deep-Blue Phosphorescent Organic Light-Emitting Diodes. J. Mater. Chem. C 2017, 5, 1651-1659.

(69) Ren, X.; Alleyne, B. D.; Djurovich, P. I.; Adachi, C.; Tsyba, I.; Bau, R.; Thompson, M. E. Organometallic Complexes as HoleTransporting Materials in Organic Light-Emitting Diodes. Inorg. Chem. 2004, 43, 1697-1707.

(70) Yamauchi, S.; Fujinami, T.; Matsumoto, N.; Mochida, N.; Ishida, T.; Sunatsuki, Y.; Watanabe, M.; Tsuchimoto, M.; Coletti, C.; Re, N. Synthesis, Structure, Luminescence, and Magnetic Properties of a Single-Ion Magnet "Mer"-[Tris(N-(Imidazol-4-Y1)-Methylidene]DL-Phenylalaninato)Terbium(III) and Related "Fac"-DL-Alaninato Derivative. Inorg. Chem. 2014, 53, 5961-5971.

(71) Dabb, S. L.; Fletcher, N. C. Mer and Fac Isomerism in Tris Chelate Diimine Metal Complexes. Dalt. Trans. 2015, 44, 44064422 . 